\title{
University of Jordan Graduate Students' Perception on Mobile Learning via WhatsApp and its Role in Easy Accessibility and Interaction with Instructional Content
}

\author{
Halah Ata Allah Abdel Ra'oof Awadh
}

\begin{abstract}
The study aimed to identify the perceptions of postgraduate students at the University of Jordan about mobile learning through WhatsApp and its role in easy accessibility and interaction with instructional content. The individuals of the study were selected purposively sampling approach among graduate students at the University of Jordan including (25) students from Faculty of Educational Sciences and King Abdullah II College of Information Technology during the first semester of the academic year 2018/2019. The researcher used the qualitative research approach for achieving the purpose of the current study. The researcher has prepared an interview sheet with quasi-standardized questions for data collection purposes. The study questions were answered by using the holistic content analysis approach for the responses of quasi-standardized interview questions as well as qualitative methods such as frequencies. The results of the current study revealed that; postgraduate students have positive perceptions about the application of WhatsApp and its role in accessibility and interaction with the instructional content. In addition to the contribution of WhatsApp application was efficient and highly effective in easy and interaction with instructional content, where the application of WhatsApp has achieved the desired positive effect on students' accessibility and interaction with the instructional content. This has been demonstrated by the high level of satisfaction among the students in WhatsApp application and its use in their educational-learning process.In light of the results of the current study, the study provided several recommendations; the most important of which is the necessity to activate WhatsApp application in a systematic and thoughtful manner to be adopted as a formal educational learning tool, giving it a wider space, and deeper tasks to enrich the educational process and raise awareness of Jordan university students about its benefits and uses that can be provided to support the educational - learning process.
\end{abstract}

DOI: $10.7176 / \mathrm{JLPG} / 103-11$

Publication date: November $30^{\text {th }} 2020$

\section{Introduction}

Technology and social media have spread in the current era, as the vast distances between peoples have been brought closer, overcoming the different languages, customs and cultures, and all barriers have been overcome between the convergence of ideas and goals, as technology, means of communication, mobile devices and the Internet have all become a necessity of the current time. The world has reached a point where social communication devices and the Internet cannot be overlooked or separated from the student's life, so it was more appropriate to adapt scientific progress to serve the learner, taking advantage of the current generation's attachment to the Internet, their phones or computers.

In light of the new generation's preoccupation with everything related to the Internet, the process of learning and education has taken a wide range of peoples' attention, as it reflects the manifestations of civilization and advancement. Chan \& Elliott (2004) pointed out that learning is a process that occurs when the student receives information from the teacher or textbooks as a source, whereby a student is the active and effective member where he is responsible for acquiring information and experience, while teacher 's role is limited to guiding, directing and leading the teaching-learning process.

The theories of learning as seen by Iskandar and Ghazzawi (1994) indicate that learning is an individual issue, so the learner must use his way of thinking, depending on his desire and ability, which provides an opportunity for slow learning and provides a treatment for individual differences, and helps to increase interaction between teachers and students.

Learning was supported by modern educational strategies and methods that depend on the use of technology and the Internet as it conquered the world with its effectiveness, speed and ease of use, including phones and mobile devices that contributed to the teaching-learning process, as Telecom Learning played an important and effective role, because of its characteristics and advantages as stated by Al-Dahshan (2015), as it is used everywhere and at any time, in addition to its ease of use, and it is carried in the pocket, and transferred with the user.

Al-Dahshan defined Telecom Learning as "the use of mobile devices, ICT devices, mobile devices, laptops, tablets, iPads, and personal digital assistants in the process of teaching and learning anytime and anywhere" (AlDahshan, 2015).

In order to provide this feature in Telecom Learning, it has become one of the most important and latest 
methods of learning, whose methods depend on mobile educational media, especially the mobile phone, as mobile learning was used in universities and countries in a number of projects, and an example of the beginnings of this use is the (Telecom) wireless project for mobile learning. (Telecom Learning), which was established in Norway in (2000), and played an active role in E-learning and Telecom Learning (Keegan, 2000). The objectives of the project at that time were to use simple wireless solutions for normal distances in the field of classrooms, sending materials, and taking exams (Quiz), and course evaluation (Slim, 2012).

On the level of education in Jordan, Al-Shami (2009) indicated that an experiment was conducted to use mobile devices in teaching and learning at Jadara University in 2009, by training students and professors to develop educational content using mobile devices, as the electronic educational content became available on mobile devices, online, and on paper at the same time, and short text messages were used to send messages to students to inform them the sites through which the educational files are downloaded to their mobile phones.

Accordingly, the importance of integrating technology into education, whether in schools or universities, stems. This study attempts to investigate the perceptions of postgraduate students at the University of Jordan of Telecom Learning through WhatsApp regarding ease of access and interaction with educational content.

\section{Study problem and questions}

Although the use of mobile devices by university students, they remain in students' pockets without using them for learning. Since the researcher is a postgraduate student in the Faculty of Educational Sciences at the University of Jordan, she faced some difficulties, like other students, in accessing, exchanging, or interacting with educational content, so the problem of this study is to research the perceptions of postgraduate students at the University of Jordan for Telecom Learning through WhatsApp ,as it provides easy access to and interaction with educational content.

Accordingly, this study seeks to answer the following questions:

- What are the perceptions of postgraduate students at the University of Jordan about Telecom Learning through WhatsApp and its role in facilitating access to educational content?

- What are the perceptions of postgraduate students at the University of Jordan about Telecom Learning hrough WhatsApp and its role in interacting with educational content?

\section{Objectives of the study}

This study aims to:

1. Identify the perceptions of postgraduate students at the University of Jordan about Telecom Learning through WhatsApp and its role in facilitating access to educational content.

2. Identify the perceptions of postgraduate students at the University of Jordan about Telecom Learning through WhatsApp and its role in interacting with educational content.

\section{Importance of the study}

Theoretical importance:

- This study shows the importance of information and communication technology tools and their use in the teaching-learning process.

This study opens the way for researchers to work on conducting studies related to the subject of the study.

\section{Applied importance:}

- The importance of the current study lies in the possibility of using new and highly effective teaching methods through mobile phones and its various applications, including the WhatsApp application, the focus of this study.

- Encouraging postgraduate students at the University of Jordan to use their mobile phones to facilitate their teaching-learning journey and to activate it to access and interact with educational content.

- This study benefits decision-makers in using WhatsApp as a technology to access educational content to students, especially in crisis conditions, in which students cannot access universities and use distance learning.

\section{Study terminology and procedural definitions}

Effectiveness: Effectiveness is defined idiomatically in "Al-Mu'jam Al-Wasit" Dictionary as "A description of all things that are active" (Mustafa; Al-Zayat; Abdel-Qader; Al-Najjar, 1972: p. 695). The researcher defines "Effectiveness" procedurally as "the extent to which Telecom Learning, through the use of the WhatsApp application, contributes to the ease of access and interaction with educational content for postgraduate students at the University of Jordan.

Telecom Learning: Telecom Learning has been defined as "the use of mobile devices in the teaching and learning process, as it focuses on using the technologies available with wireless communication devices to deliver information outside the classroom" (Al-Dahshan, 2015: p.25). The researcher defines "Telecom Learning" procedurally as "a form of electronic learning in which small and hand-held wireless devices are used, 
such as: mobile phones, smart phones, and in which communication is made using the WhatsApp service in order to facilitate the process of students' access and interaction with educational content.

Whatsapp: It is an application that contains all the characteristics of common chat programs on computers and makes them in one application that is portable via the mobile device. It is a social networking application through which we can communicate with everyone who owns the same application on his mobile device, regardless of his location, near or far. The application only requires accessibility to the Internet to keep you in constant and immediate contact with whom you want to correspond with (Musallam, 2014). The researcher defines "WhatsApp" procedurally as "an application that is downloaded to mobile phones and mobile devices, used in social communication through SMS or image messages, and videos can be sent through it, relying on the Internet, without any financial cost when sending and receiving messages.

Interacting with educational content: the researcher defines it procedurally as "mutual operations between two or more parties, through the WhatsApp application, during which educational content is exchanged in all its forms - text, image, or video - with the aim of communicating to achieve a common goal.

Limitations of the study: The results of this study were determined as follows:

1. Spatial limits: The University of Jordan.

2. Temporal limits: the academic year (2019/2020).

3. Human Limits: Postgraduate students at the University of Jordan who use the WhatsApp application.

\section{Theoretical framework and literature review}

The increasing use of mobile devices such as (Laptop, Tablet), (iPad), (Mobilephone) contributed to the employment of mobile learning environments in the teaching-learning process, as they are being used in the current era more highly than ever before, in light of the acceptable prices, because they are linked and connected to the Internet, and communication network. These devices have a high capacity for storing data and images, and downloading applications that are compatible with their features. Mobile devices, especially mobile phones, can be employed through the issuance and development of software and files that include educational programs that can be used, view and read their scientific content, and it may reach an unlimited number of students in different places. In this way, good services are provided to individuals and the educational system, what indicates that mobile phone technologies represent a natural extension of long-term learning in light of the restrictions imposed on the learner, such as lack of time and different conditions for learning, all of these things are positive indicators that ( Mobile Educational Systems) is a major factor in the educational-learning environment, which increases the level of continuous learning (Al-Dahshan and Yunus, 2010).

Mobile phones are characterized by their high capacity of communication between individuals anywhere and at any time, which assists in the communication of different ages categories and multiple scientific qualifications, as well as the participation between students and individuals of the teaching-learning process without the need to meet face to face. It helps to provide the best types of learning. Through mobile devices, it is also possible to store the vast amount of information, data, books, image s, summaries, and references necessary for the teaching and learning process, and mobile devices help to make learning a pleasure, through the introduction of sound, image, and video technology. The mobile phone provides students and educated individuals with an educational context for long periods of time, as the mobile phone use technologies such as (memory capacity, speed in data and information recovery, reading, color images, and controlling the size of screens), which allowed different learning environments to benefit from them (Al-Dahshan, 2013).

\section{WhatsApp}

WhatsApp has emerged in the field of social networking and chatting. WhatsApp was launched for the first time in 2009 by Brian Acton and Jan Koum, and like any new innovation, this application dazzled its users and found wide demand in various social, media, economic and other fields. Newton (2013) believes that WhatsApp is one of the most popular programs and applications that are loaded on mobile smartphones around the world, as it is used by hundreds of millions of smart phones, superior to all some of the other means of communication widely used, such as Twitter.

Al-Katib (2011) believes that this application has dazzled everyone who used it, but that the characteristics of this application have made it difficult to dispense with or not use it, because it is suitable for all ages, cultures and environments, and because of its ease of use and flexibility, as it shortens a lot of time and effort. WhatsApp application has attracted the attention of researchers in all fields, including the educational field, especially with the recent spread of the concept of mobile learning. El-Sherbiny (2013) pointed out that the electronic chat process still attracts many different groups of youth (including university students), who use it under any circumstances and at any time even during academic lectures, and the reason for this is that the chatting process is quite "fun", as we will not be able to exclude the WhatsApp application from the lives of our children, youth and students, but it is better to become familiar with it as a useful application of the teaching-learning process. 


\section{Educational content:}

Because of the importance of educational content, it was necessary to follow deliberate methods within certain criteria for choosing it, which are clear, and able to reach the desired teaching-learning goals with the least time and effort. There were two trends in choosing educational content in the curriculum as reported by Al-Hashemi and Attia (2009). The first trend represented in choosing a quantity of knowledge and presenting it to educated individuals in logical systems, without referring to specific goals, where priority is specific to the educational material only, and the second trend focused on setting prior goals, followed by determining the appropriate content to achieve the goals (Jamal, 2000).

Since the current study deals with mobile learning through WhatsApp and its role in ease of access and interaction with educational content, it is worth noting the electronic content that is being adopted in mobile learning.

\section{Literature review}

Al-Azmi (2017) conducted a study that concluded that there is a positive trend among respondents about WhatsApp's contribution in both the social and religious aspects, and the existence of a difference between the sample individuals about the contribution of WhatsApp in both the educational and the political aspect. The results also showed that there are statistically significant differences between the sample individuals according to the gender variable in the field of the political side in favor of males, and the existence of statistically significant differences between the sample individuals according to the social status variable in the social aspect in favor of the married person, and the presence of statistically significant differences between the sample individuals according to the specialization variable in the field of the religious side in favor of literary specialization, and the absence of statistically significant differences between individuals according to the governorate variable in any field of study.

As for the study of Al-Rawi (2016), it found that there were statistically significant differences between the control group and the experimental group at the level of student achievement and in favor of the first experimental group, and the presence of statistically significant differences between the control group and the experimental group at the level of student achievement and in favor of the second experimental group, and the lack of statistically significant differences between the first experimental group and the second experimental group. It was found that there were statistically significant differences between the control group and the first experimental group at the level of students 'retention of information, where the differences were in favor of the first experimental group, and the presence of statistically significant differences between the control group and the first experimental group on the level of students' retention of information, and the differences were in favor of the second experimental group.

Zahid's (2016) study found that there was a high effectiveness of applying a strategy of reverse instruction using Blackboard and WhatsApp for the benefit of the experimental group compared to using the lecture by the control group. The study also found a high indication of a trend towards Internet-based education in favor of the experimental group versus the control group.

Centinkaya's (2017) study showed that WhatsApp is able to provide an educational environment, but in an unstructured way, and therefore, by taking the benefits and harms of using WhatsApp, it is advisable to support and monitor the use of this application in the field of learning.

Ashiyan's study (2016) showed the superiority of the experimental group that relied on using WhatsApp in school work over the control group. This study showed that the mobile phone was an effective learning tool.

The study of (Abaido \& Elmessiry, 2016) concluded that there were differences between the regular teaching method (face-to-face teaching) and the e-learning method applied through WhatsApp. Indicators showed that the learning environment is affected by many variables, and accordingly, there is an increasing need to develop new, creative and innovative teaching methods that make experiences more attractive and engaging.

(Albers, Davison, Johnson, 2015) conducted a study that showed students change their preferred learning tool to WhatsApp over the course of the semester. Students provided qualitative data on why they preferred WhatsApp. Students made presentations and posters on how WhatsApp can help them collaborate to complete IBL projects, and the study results illustrate how WhatsApp can be a successful mobile learning tool for students' collaboration in inquiry-based learning.

\section{Study methodology}

A qualitative research method was used in this study because it is appropriate for the purposes and objectives of the study.

\section{Study sample}

The sample of the current study consisted of postgraduate students at the University of Jordan, who use the WhatsApp application in the teaching-learning process. The study sample were chosen by purposive method 
among some students in the Faculty of Educational Sciences and King Abdullah II Faculty of Information Technology, amounting (25) students. They were personally interviewed in their places of residence and accredited as a case study.

\section{Study tool}

The interview method was adopted to answer the study questions. The semi-standardized interviews were conducted to identify the perceptions of postgraduate students at the University of Jordan about mobile learning through WhatsApp and its role in interacting with educational content, as the following interview questions were formulated in the study tool:

- How do you use your mobile phone through WhatsApp to facilitate the exchange of educational assignments related to educational content?

- $\quad$ From your point of view, what are the teaching-learning uses that WhatsApp mobile learning contributes to?

- What kind of electronic files have you received on your mobile phone through WhatsApp?

- What are the most prominent WhatsApp services that you used in your university courses?

\section{Validity of the study tool}

The semi-standardized interview questions were submitted to a number of experts who are individuals of the teaching staff in the specialization of Instructional Technology, Curriculum and Teaching, Measurement and Evaluation, and Information and Communication Technology at the University of Jordan and other universities, in order to express their views on the interview questions. Based on the opinions of experts, some questions in terms of wording have been modified and corrected to increase their clarity. Based on the opinions of the experts and their modifications, the validity of the content of the study tool and the relevance of its paragraphs were verified. The experts expressed their desire to interact with the questions, which indicates the apparent validity of the tool.

\section{Data analysis}

SPSS statistical analysis program was used, and frequencies and percentages were extracted to describe the responses of the study individuals.

\section{Results}

The results of the first question: What are the perceptions of postgraduate students at the University of Jordan about mobile learning through WhatsApp and its role in facilitating access to educational content? The first question was answered through the first and second interview questions as follows:

- Results related to the first interview question: How do you use your mobile phone through WhatsApp to facilitate the exchange of educational assignments related to educational content?

To answer the first question, the frequencies and percentages were extracted, to identify the use of the mobile phone through WhatsApp in facilitating the exchange of teaching-learning assignments related to educational content, and Table (1) shows this:

Table (1) The use of a mobile phone through WhatsApp to facilitate the exchange of teaching-learning assignments related to educational content

\begin{tabular}{|c|c|c|}
\hline $\begin{array}{c}\text { The Study Tool: The use of a mobile phone through WhatsApp to facilitate } \\
\text { the exchange of educational assignments }\end{array}$ & Frequencies & Percentages \\
\hline Creating groups & 24 & 46.2 \\
\hline Taking photos & 3 & 5.8 \\
\hline Uploading and transferring files & 12 & 23.1 \\
\hline Chatting and exchanging of information & 13 & 25.0 \\
\hline Total & 52 & 100.0 \\
\hline
\end{tabular}

The results of Table (1) showed that the use of the mobile phone through WhatsApp facilitates the exchange of teaching -learning assignments related to educational content, and WhatsApp has been contributing to this facilitation through multiple technologies.

Students expressed this in their responses by creating groups of students, and with the participation of a faculty member within the university, to exchange assignments and communicate information to each other, with a rate of $(46.2 \%)$ of the responses of the study individuals .

The results showed that WhatsApp contributes to the exchange of teaching -learning assignments also through the imaging technique, so the student can photograph the papers and documents that contribute to increasing information among the students and send them via WhatsApp, and the consensus was that of $5.8 \%$ of the study individuals.

It was found that WhatsApp contributes to facilitating the exchange of assignments related to educational 
content by downloading files and sending them or transferring them from one student to another. This was evident by the responses of the study individuals, at a rate of $(23.1 \%)$ of them.

It was noted that WhatsApp contributes to facilitating the exchange of teaching -learning assignments related to educational content by using the technology of chats and information exchange, with a rate of $(25 \%)$ of the responses of the study individuals.

These technologies expand the sharing of information and knowledge about the teaching-learning assignments related to the educational content, as the student can learn about the information by looking at the data and publications that the group shares, so each student can enter new information, which contributes to raising the level of knowledge of many students, as this information and research exchange is transmitted from one student to another quickly and at the lowest costs via the Internet in general and WhatsApp in particular. This is due to the great importance of the application of WhatsApp and the flexibility of its services that facilitate the exchange of teaching -learning assignments related to educational content, as teaching -learning assignments are part of the educational content, which is a very important part. Creating groups showed its effectiveness and importance in the teaching-learning process, because of its significant impact on sharing and exchanging knowledge, leading to educational content.

Findings related to the second interview question: From your point of view, what are the teachinglearning uses that WhatsApp mobile learning contributes to?

To answer the second question, the frequencies and percentages were extracted, to identify the teaching -learning uses that mobile learning through WhatsApp contributes to, and Table (2) shows this:

Table (2) Teaching - Learning uses that mobile learning through WhatsApp contributes to.

\begin{tabular}{|c|c|c|}
\hline $\begin{array}{c}\text { Teaching - Learning uses that mobile learning through WhatsApp } \\
\text { contributes to }\end{array}$ & Frequencies & Percentages \\
\hline Dialogue and discussion (brainstorming) & 23 & 39.6 \\
\hline Sharing knowledge and sharing experiences & 21 & 36.2 \\
\hline Communicate with a faculty member & 14 & 24.2 \\
\hline Total & 58 & 100.0 \\
\hline
\end{tabular}

The results of Table (2) show, and by interviewing students with several majors at the University of Jordan (individuals of the study), their opinions about the teaching-learning uses that mobile learning through WhatsApp contributes to. After reviewing the students 'responses, it became clear unanimously that the teaching-learning uses through WhatsApp were centered around dialogue and discussion (brainstorming) with a rate of $(39.6 \%)$ of the responses of the study individuals, freely expressing opinions, and raising the level of freedom in expressing opinions and perceptions which students cannot show in the classroom and in front of a faculty member - for fear of embarrassment.

The sharing of knowledge and the exchange of experiences had a rate of $(36.2 \%)$ of teaching-learning uses in which mobile learning through WhatsApp contributes to the collective circulation and discussion among students on subjects related to the study materials and their discussion, and many students gaining new friendships, which contributed to the increase and participation of Knowledge and information of students and paving the way for them to exchange the vast amount of information about the way to download files and image $\mathrm{s}$ that benefit the students and enhance the teaching-learning process for them.

The results also showed through the interviews that mobile learning through WhatsApp is extremely important in opening the discussion between students and a member of the teaching staff, at various times and outside the classroom, with $(24.2 \%)$ of the responses of the study individuals, because it is very difficult to discuss with a faculty member for a long time due to the limited period of lecture time.

Also, a student cannot use the lecture time to his advantage, as there are many students who have their many and varied questions and inquiries, but WhatsApp enabled the students to communicate with a faculty member to gain information outside the lecture time without harassing others and giving the faculty member the opportunity to respond at any time and a student is ready to answer questions to deliver correct information to students. This may be attributed to the diversity and flexibility of the services provided by WhatsApp, in addition to that WhatsApp is an application available on all mobile devices, which in turn contributes to accessing the largest amount of educational content.

The results of the second question: What are the perceptions of postgraduate students at the University of Jordan about mobile learning through WhatsApp and its role in interacting with educational content?

The second question is answered through the third and fourth interview questions as follows:

Results related to the third interview question: What kind of electronic files have you received on your mobile phone through WhatsApp?

To answer the third question of the interview, the frequencies and percentages were extracted, to identify the type of electronic files that students receive on their mobile phones through WhatsApp, and Table (3) shows this: 
Table (3) Types of electronic files that students receive on their mobile phones through WhatsApp

\begin{tabular}{|c|c|c|}
\hline $\begin{array}{c}\text { Types of electronic files that students receive on their } \\
\text { mobile phones through WhatsApp }\end{array}$ & Frequencies & Percentages \\
\hline Video files & 10 & 9.4 \\
\hline Images files & 14 & 13.2 \\
\hline PDF Files & 22 & 20.8 \\
\hline Word doc. & 21 & 19.8 \\
\hline Excel & 10 & 9.4 \\
\hline SPSS & 1 & 0.9 \\
\hline Voice Record & 9 & 8.5 \\
\hline PowerPoint & 12 & 11.3 \\
\hline Links & 7 & 6.6 \\
\hline Total & 106 & 100 \\
\hline
\end{tabular}

The results of Table (3) showed the diversity of electronic files received by students on the mobile phone through WhatsApp, which facilitates the exchange of teaching -learning assignments related to educational content. The students expressed this in their responses through the interviews that were conducted with them, where it was found that the video files facilitated access and interaction with the educational content by $9.4 \%$ of the responses of the study individuals, as the visual materials can deliver the information to the students quickly and in a short time, which is one of the students favorite methods.

The results showed that the image files contributed to understanding educational materials at a rate of $(13.2 \%)$ of the responses of the study individuals , as images played an effective role in disseminating information and communicating it accurately, in short spaces on the mobile phone, and this increases students 'knowledge and positive interaction with the educational content of the materials. .

It was noted that the (PDF) files were among the files that reached the most students, as they scored (20.8\%) of the responses of the study individuals. This may be due to the fact that this type of file contains the largest amount of information in light of the small size of the file on the memory of the mobile phone, and this type of files can preserve the formatting and general appearance of the original files without any defect or change in the shape of the images and the text they contain.

The results showed that word processing files (Word doc) scored a percentage of (19.8\%) of files that students received, and this type of files is the most common among students, which can communicate information to students in the least size of the memory of the mobile phone, and this type of files is for texts that contain information, images, tables, and data related to teaching-learning contents.

It was also found through the results that students receive of electronic tables (Excel) by (9.4\%) from the responses of the study individuals, and this type of files is for data, numbers and tables that are used for analysis or entering data for information that benefits the students, and also this type of files is small in size and can collect information that will benefit students. Also, this type of file is small in size and can collect a lot of data that contributes to easy access to educational content and interaction with it.

It was noticed that only $(0.9 \%)$ and with (1) frequency, of the responses of the study individuals were receiving the Statistical Package for Social Sciences (SPSS) file, and this type of files is very useful for analyzing data statistically in the practical side of studies, which is also important in research and studies, master's and doctoral theses.

(8.5\%) of students were receiving Voice Record of the responses of the study individuals, and this type of files contributes to ease of access and interaction with educational content through recording lectures, students 'opinions, some recordings of external professors and lecturers, which increase students' knowledge and culture.

As for the PowerPoint files, they scored (11.3\%) of the responses of the study individuals, and this type of files is very important in conveying the main ideas of the materials and lectures and summarizing them scientifically (summaries) and presenting them in the form of slides to facilitate the study and interaction with the educational content.

Finally, it was found that $(6.6 \%)$ of the responses of the study individuals confirmed their reception of electronic links (links). These links contain many files that may be visible, audible, or presented in the form of slides that lead students to the information they need and search for. These links also help students to interact with the educational content.

These files contribute to interacting with the educational content, as the student can download these files and store them on the mobile phone, which do not take much space from the memory, and at the same time they contain the vast amount of information and data that the student benefits from, and this may be attributed to that these files contain the largest amount of information in light of the small size, which does not take up much space on the memory of the mobile phone. 
Results related to the fourth interview question: What are the most prominent WhatsApp services that you used in your university courses?

To answer the fourth question of the interview, the frequencies and percentages were extracted, to identify the most prominent WhatsApp services that students benefited from in their university courses and which contribute to facilitating the exchange of didactic-learning duties related to educational content, and Table (4) shows this:

Table (4) The most prominent WhatsApp services that students have benefited from in their university courses.

\begin{tabular}{|c|c|c|}
\hline $\begin{array}{c}\text { The most prominent WhatsApp services that are useful in the university } \\
\text { course }\end{array}$ & Frequencies & Percentage \\
\hline Send the same message to multiple contacts simultaneously & 11 & 10.8 \\
\hline Determining the person the most you talk to & 4 & 3.9 \\
\hline Find out and reduce the amount of data the app is using & 1 & 1.0 \\
\hline Mute group chats & 13 & 12.7 \\
\hline Share documents & 1 & 19.6 \\
\hline Determine which personal information anonymous users can see & 20 & 2.9 \\
\hline Read incoming messages without showing blue mark & 3 & 2.9 \\
\hline Prevent photos and videos from automatically saving themselves on the phone & 3 & 2.9 \\
\hline Add dates to the user's calendar & 3 & 1.0 \\
\hline Add the shortcut for individual chats to home screen & 1 & 19.6 \\
\hline Using the WhatsApp application on the computer & 20 & 19.6 \\
\hline Transfer files between a phone and a computer & 20 & 1.0 \\
\hline Chat protection & 1 & 1.0 \\
\hline Writing in bold, italic, or with a line between the letters & 1 & $\mathbf{1 0 0 . 0}$ \\
\hline Total & $\mathbf{1 0 2}$ & (1) \\
\hline
\end{tabular}

The results of Table (4) showed the diversity of WhatsApp application services that are useful in the university course and that contribute to ease of access and interaction with educational content. Through interviews with postgraduate students, it was found that WhatsApp is primarily useful for sharing documents, using the WhatsApp application on a computer, and transferring files between the phone and a computer, and these services scored a rate of (19.6\%) for each of them from the responses of the study individuals with a frequency of (20 out of 25) individuals, confirming unanimity on these services

Silencing group chats came with (12.7\%) from the responses of the study individuals , as this service helps to reduce the inconvenience that may cause confusion for the student during the study. The services of sending the same message to multiple contacts in one unit came as one of the important services, as it scored a rate of $(10.8 \%)$ of the responses of the study individuals , this gives the student the time needed to study, and reduces the time wasted as a result of sending messages each individual separately. The service of determining the person the most you talk to scored rate of $(3.9 \%)$ of the responses of the study individuals. This service helps that the person who is being spoken to has good information and useful information that helps students in the study.

Then came the services of reading incoming messages without showing blue mark, and to prevent pictures and video clips from automatically saving themselves on the phone, and adding dates to the used calendar at a rate of $(2.9 \%)$ each.

Finally, the services that are less used and that have the least frequency for students, and that scored a rate of $(1 \%)$ of the responses of the study individuals , which is (Find out and reduce the amount of data the app is using, determining the personal information that anonymous users can see, determine which personal information anonymous users can see, chat protection, writing in bold or italics or with a line between the letters, these are among the few services that benefit students in university courses.

\section{Recommendations:}

The current study recommended the necessity of activating the WhatsApp application in a systematic and thoughtful manner in order to adopt it as an teaching-learning formal method, and to give it a wider space, and deeper tasks such as its adoption as a formal means to aid in education to enrich the teaching-learning process, in addition to educating students at the University of Jordan about the benefits and uses that WhatsApp can offer to support the progress of the teaching-learning process.

\section{References}

Abaido, G. and Elmessiry, H. (2016). Efficiency of WhatsApp as a Means of Disseminating Educational Information, UoB Journal - Oman, https://pdfs.semanticscholar.org: 26-28/9/2016. pp1-5.

Al-Azmi, Najla (2017), Views of Kuwait University students who use WhatsApp on its contributions to social 
and educational aspects and his relationship to some variables, Journal of Gulf and Arabian Peninsula Studies, 43 (165) 220-245.

Albers, R. Dvison, C. and Johnson, B. (2015). Inquiry - Based Learning: Emirati University Student's Chose WhatsApp for Collaboration. Learning and Teaching in Higher Education: Gult Perspectives, 14 (2): 41-52.

Al-Dahshan, Gamal (2013), The use of mobile phones in education between support and rejection, a symposium on higher education systems in the era of competitiveness, Kafr El-Sheikh University, Egypt.

Al-Dahshan, Jamal (2015), Teaching and Learning in the light of Mobile Devices, Cairo: Joanna Publishing.

Al-Dahshan, Jamal and Yunis Majdi, (2010), Mobile Learning, a new formula for distance education, the International Conference of the Oman Society for Education Technology, 6-8 December 2010, Sultanate of Oman

Al-Hashemi, Abdul-Rahman; And Attia, Mohsen (2009), Content Analysis of the Arabic Language Curricula, a vision of application theory, (1st ed.), Amman: Dar Safa for Publishing and Distribution.

Al-Katib, Saud (2011), New Media and Community Issues / Challenges and Opportunities. The Second Islamic Media Conference, King Abdulaziz University, Saudi Arabia.

Al-Mataani, Ali (2014), How do we benefit from WhatsApp to bredge the gap between school and home, AlQalam Magazine. https://alqalm.com.

Al-Rawi, Dhamia (2016), The effect of using some mobile phone technologies on the achievement of chemistry among students of the College of Education for Pure Sciences, Ibn al-Haytham, and their precedence of information, the works of the Eleventh International Conference: Learning in the Era of Digital Technology - Center for the Generation of Scientific Research, Lebanon, Tripoli.

Al-Shaheen, Ammar (2012), "Social Media is the Power of Influence and Change," in: Sawt al-Basra electronic newspaper, January 24, 2012, at the link: http://basvoice.com/ar/news.php-?action= view @ id=4815.

Al-Shami, Ammar (2009), The Application of Mobile Education, Its Concept, Importance, and Challenges to the Students of the Jordanian University of Jadara, Conference on Informatics and Arab Development Issues, (1st Edition), Alexandria University: Dar Al-Jami Al-Hadith.

Ashiyan, Z. (2016). Impact of WhatsApp on Learning and Retention of Collocation Knowledge Among Iranian EFL Learners, Advances in Language and Literary Studies. 7 (5): 113-127.

Cetinkaya, L. (2017). An Educational Technology Tool that Developed in the Natural Flow of Life Among Students: WhatsApp, International Journal of Progressive Education, 13 (2): 29-47.

Chan, K. and Elliott, R. (2004). Relational Analysis of Personal Epistemology and Conception about Teaching and Learning, Teaching and Teacher Education. 20 (12): 22-30.

El-Sherbiny, Muhammad (2013), "The Effectiveness of Cognitive-Behavioral Therapy in Serving the Individual in Alleviating the Negative Effects of the WhatsApp Program on the Educational Process", Journal of Studies in Social Work and the Humanities, 35 (1): 1-66.

https://arabitechnomedia.com

Iskandar, Kamal and Ghazzawi, Muhammad (1994), Introduction to Educational Technology, Amman: Al-Falah Library for Publishing and Distribution.

Jamal, Abd al-Rahman (2000), Curriculum Fundamentals and Methods of Development, (1st ed.), Amman: House of Approaches for Publishing and Distribution

Keegan, D. (2000). Mobile Learning: A Practical guide, Dun Laoghaire, Ireland: Ericsson.

Musallam, Issa (2014). "What is WhatsApp? What is it distinguished from similar applications?"

Mustafa, Ibrahim and Al-Zayat, Ahmed and Abdel-Qader, Hamed and Al-Najjar, Muhammad (1972), Al-Wasit Lexicon I (2), Istanbul: The Islamic Library for Printing and Publishing.

Newton, C. (2013). WhatsApp Has More Users than Twitter and More Messages than Facebook, Retriwed on November, 2013: from http://www.theverge.com-/2013/4/16/4231376/whatsapp-more-users-than-twittermore-messages-thanfacebook

Salah, Ayah (2014), Whatsapp review: The advantages and disadvantages of WhatsApp, Nine Magazine, www.ts3a.com.

Saleem, Tayseer (2012), Mobile Learning Technology, Cybrarians Journal, 28 (34) 32-40.

Telegraph Magazine (2016). 15 secret features you need to know in WhatsApp, UK https://www.noonpost.org/content/12440

Zahid, Manal (2016), The Effectiveness of the Strategy of Flipped Education Using the Blackboard System and the Application of WhatsApp on Academic Achievement and the Trend Toward the Use of the Internet in Education among Female Students of the Home Economics Department at the Faculty of Education at Prince Sattam Bin Abdulaziz University, "The Arab Journal of Science and Research Publishing, 2 (8 ): 35 53. 